\title{
Revista de História e Estudos Culturais
}

Janeiro-Junho de 2021

Vol. 18 Ano $18 n^{\circ} 1$

www.revistafenix.pro.br ISSN 1807-6971

\section{"FAZEM-SE VERSOS PRA TIRAR UM PESO": AS BATALHAS DE VITTORIO SERENI}

\author{
Patricia Peterle* \\ Universidade Federal de Santa Catarina - UFSC \\ patriciapeterle@gmail.com
}

\begin{abstract}
RESUMO: A Segunda Guerra e a reconstrução marcaram toda uma geração, assim como as transformações num país sempre mais industrializado e partícipe do sistema capitalista configuram-se como etapas relevantes das mudanças intrínsecas a um húmus social. Vittorio Sereni (1913- 1983) traz uma trajetória emblemática, tenente de infantaria do exército italiano, poeta, professor, funcionário da Olivetti e diretor da editora Mondadori. A apreensão inicial diante do conflito é suspensa quando ele é preso pelos Aliados e levado para campos no norte da África, de onde sairá somente em 1946. Sereni, portanto, não compartilha da atmosfera de seus coetâneos, os quais farão parte da Resistenza. Esse sentimento de exclusão da história atravessa sua poética, operando como uma lente singular sobre momentos da história individual e coletiva, como acontece com a industrialização na década de 1960, quando outros vivos-mortos são produzidos e esquecidos. O gesto antropológico dessa escrita, então, abarca uma complexa condição existencial vivo-morto-vivo.
\end{abstract}

PALAVRAS-CHAVES: Vittorio Sereni, Segunda Guerra Mundial, Capital, industrialização, poesia

\section{"VERSES ARE MADE TO TAKE A WEIGHT": THE BATTLES OF VITTORIO SERENI}

\begin{abstract}
The Second War and reconstruction marked a whole generation, just as the transformations in an increasingly industrialized country and the entrance in the capitalist system are relevant stages of the changes intrinsic in a social humus. Vittorio Sereni (1913-1983) brings an emblematic trajectory, infantry lieutenant of the Italian army, poet, teacher, Olivetti employee and director of the Mondadori publishing house. Initial apprehension in the face of the conflict is lifted when he is arrested by the Allies and taken to camps in North Africa, from where he will leave only in 1946. Sereni, therefore, does not share the atmosphere of his peers, who will be part of Resistenza. This feeling of exclusion from history runs through his poetics, operating as a singular lens on moments in individual and collective history, as with industrialization in the 1960s, when other living-dead people are produced and forgotten. The anthropological gesture of this writing, then, embraces a complex existential condition alive-dead-alive.
\end{abstract}

Doutora em Estudos Literários Neolatinos, pela Universidade Federal do Rio de Janeiro (2006), Pósdoutorado em História pela UNESP-Assis e em Poesia Italiana pela Università degli Studi di Genova (Itália, bolsista CAPES). É professora do Departamento de Língua e Literatura Estrangeiras e do Programa de Pós-Graduação em Literatura da Universidade Federal de Santa Catarina (UFSC). Atua como membro permanente externo no Programa de Pós-Graduação em Língua, Literatura e Cultura Italianas da Universidade de São Paulo (USP). 
Disponível em: www.revistafenix.pro.br

KEYWORDS: Vittorio Sereni, Second World War, Capital, industrialization, poetry

(Roma) Valmontone 9 de maio 43

Em Caporossi

via Nazionale 16

Meu caro Sereni,

a tua carta de 22 de abril, perto da iminente partida, depois de muitas voltas, me foi enviada de casa até aqui em cima e, agora, chega até mim. Espero que a minha chegue mais rápido e em lugar seguro. Parece-me necessário estar perto de você e iluminar a sua escura hora. Muitas das coisas que se escutam no nosso país não são verdadeiras e não são todas sinceras. $\mathrm{O}$ uniforme que você veste, os deveres aos quais é chamado a responder, os riscos na direção dos quais você segue, ou para onde já foi encaminhado, têm sua importância e sua necessidade. O lugar em que nesse momento você está aninhado com seus soldados é caro para mim, e uma parte da nossa bela Itália depende, com certeza, da sua constância, frieza de espírito, do seu saber superar as dúvidas e as hesitações. As dúvidas e hesitações pertencem aos outros, não a você, eu sei, mas talvez você sinta os reflexos: mas não pode ser que um ordenamento de batalha tenha um fim errado. E em primeiro lugar não são os homens que podem dispor das guerras, é certo, e dos destinos: mas há uma outra ordem, muito superior aos juízos humanos, que as dispõe; portanto, o homem que a elas é chamado é legitimamente o soldado da causa boa. Lembro-me destes panos de tenente cinza-esverdeados quando os usei, quanto me eram caros enquanto a guerra durou. Eles são e serão sempre a nobre farda de um dever que é comandado pelos homens não menos do que pelo elementar dever de viver. Espero que você abra essa carta em lugar seguro e que sinta que a escrevi com sentimento de reconhecimento de um pai diante de seu filho exposto para defendê-lo. Faça você o que eu deveria ter feito, se tivesse a sua idade, e que fiz, e que não foram as ideias dos outros que me fizeram bem ou mal, mas o débito que tem a juventude de pagar um tributo, qualquer que seja, pesado à sagrada herança de uma terra pela qual fomos gerados. Desde que começou a passar por duros agravos, seus versos são mais bonitos, e você será melhor poeta do que aqueles que não se viram com você. Qualquer coisa que precisar pode me pedir, porque a farei com prazer. Qualquer um que negar a importância do que você está fazendo agora, está de má fé ou não o diz pensando 
Disponível em: www.revistafenix.pro.br

seriamente com o coração. Um abraço, te desejo tudo de bom e sou o seu

Betocchi

(SERENI; BETOCCHI, 2018, p. 25)

Essa carta escrita por Carlo Betocchi (1899-1986) e endereçada a Vittorio Sereni (1913-1983), duas personalidades importantes do panorama cultural italiano da segunda metade do século XX, rasga o presente trazendo um momento específico que nos coloca em direto contato com uma parte crucial da história mais recente, a Segunda Guerra Mundial. Dois poetas e escritores, mas também duas gerações, duas guerras que incidem na geografia física e existencial, individual e coletiva. ${ }^{1} \mathrm{O}$ primeiro não se encontra diretamente envolvido no conflito da década de 40. Carlo Betocchi, de fato, participou da Primeira Guerra, foi enviado ao fronte antes da retirada de Caporetto $^{2}$ e integrou a chamada primeira resistência no Piave, na fronteira entre o Trentino e o Veneto, onde se enfrentaram o exército italiano (o regio esercito italiano) e as forças do império alemão e do império austro-húngaro. Já o segundo, Vittorio Sereni, destinatário da carta, encontra-se dentro do olho do furacão.

Sereni é recrutado em outubro de 1941 e é enviado para a chamada Divisão Pistoia, que havia sido reestruturada como divisão de infantaria auto-transportável. Na primavera europeia de 1942, essa Divisão, via Lubiana-Belgrado, é enviada para a Grécia com o escopo de chegar à África. Porém, depois de quatro meses em Atenas, se vê obrigada a regressar à Itália porque a passagem para a África estava bloqueada pela contraofensiva inglesa premiada pela vitoriosa batalha de El Alamein. ${ }^{3}$ Esse retorno de Sereni para a Itália, sem ter alcançado o destino previsto, está registrado na carta de 18 de janeiro de 1943, endereçada a Luciano Anceschi, amigo desde o período

1 Além da correspondência com Vittorio Sereni, é importante mencionar a intensa correspondência de Betocchi com outros poetas como Mario Luzi e Giorgio Caproni.

2 A Batalha de Caporetto é conhecida como a maior derrota do exército italiano, a ponto de a palavra "Caporetto" passar a ser usada comumente para designar uma grande derrota em outros âmbitos que não o bélico. O texto L'anno di Caporetto, publicado em 1967 pela editora Il Saggiatore e reeditado em 2014 pela Raffaeli, é fruto dessa experiência.

3 A batalha de El Alamein, outubro-novembro de 1942, conduzida pelo general inglês Montgomery, bloqueou as tropas do Eixo a quase cem quilômetros de Alexandria, no Egito, obrigando-as a se dirigirem para a Líbia, com isso ficou liberada a chegada no Marrocos e na Argélia das tropas americanas (novembro de 1942), que em julho de 1943 chegariam ao norte da África e depois na Sicília. 
universitário, junto com Antonia Pozzi, Remo Cantoni e Enzo Paci. Anceschi, com o qual Sereni mantém uma intensa e frequente troca epistolar, é crítico literário e organizador da importante antologia Lirici Nuovi (1943). Na correspondência citada, chama a atenção, na parte final, a expressão "Eu espero" (SERENI, 2013b, p. 153), que será uma condição extrema vivida por ele desde o momento em que é convocado para guerra. O poeta de Frontiera (1941) diz esperar o fim da guerra, fala da vontade de ler, de escrever, da paixão pela vida, diz ainda que gostaria de ensaiar algo do período transcorrido em Atenas, cidade "contrastante e voluptuosa". Tal vontade é depois realizada em Diario d'Algeria (1947), livro publicado no pós-guerra que inclui o poema Italiano in Grecia [Italiano na Grécia], que traz o que ele preanuncia a Anceschi (a correspondência com ele só será retomada no verão de 1946).

Passados alguns meses do retorno de Atenas, Sereni é enviado para a Sicília, onde estava programada outra partida para a África, que não se concretiza por causa do bombardeio ao aeroporto de Castelvetrano. A Divisão, portanto, é transferida para Trapani para que, via mar, possa chegar ao destino previsto. O cartão postal enviado a Carlo Betocchi, em 22 de abril de 1943, faz referência a essa transferência para a Sicília: "li seu artigo poucas horas antes da partida para a zona de operações. Agora é possível dizer que estou logo atrás das retaguardas na espera de ir para a linha" (SERENI; BETOCCHI, 2018, p. 22). ${ }^{4}$ E continua Sereni já estabelecendo um limiar entre um antes dessa experiência no fronte e um depois, sua vivência ali, que não terminará com a captura dele e de outros companheiros pelo exército Aliado: “A 'outra pessoa' $[\ldots]$ me acompanhou até aqui e talvez nas próximas horas voltará atrás rumo ao doce lago e à minha terra lombarda; não poderia suportar tanto estrondo e horror" (SERENI; BETOCCHI, 2018, p. 22). A outra pessoa refere-se ao próprio Sereni, mas ao Sereni antes da guerra, daqui as duas referências que evocam o espaço geográfico da infância e da juventude, o lago Maggiore da cidade de Luino, no norte da região italiana da Lombardia, na fronteira com a Suíça; imagens que marcam sua poesia desde o primeiro livro, cujo título já aponta para uma vivência que se dá, justamente, no limiar, Frontiera, em que a matéria aquosa, o vapor áqueo têm uma presença relevante.

A última correspondência trocada entre Betocchi e Sereni antes da prisão consiste em outro cartão postal, de 21 de junho de 1943, quando o batalhão ao qual

4 Todas as traduções das citações são minhas, com exceção de quando é dada outra indicação. 
Disponível em: www.revistafenix.pro.br

pertencia Sereni já havia sido destinado à defesa das costas de Trapani, na ponta ocidental da Sicília. ${ }^{5}$ Nas poucas linhas escritas, o poeta afirma não ter mais nem tempo nem possibilidade para escrever, agora está na primeiríssima linha de batalha. Depois da queda de Mussolini no final de julho de 1943, os Aliados desembarcam na ilha italiana, e depois do armistício, em 8 de setembro de 1943, Sereni é levado para um campo de prisioneiros na África do norte, em Oran, na Argélia, então Marrocos francês. A correspondência entre os dois é suspensa e só é retomada, depois da guerra, em junho de 1947. O diálogo com outros amigos e intelectuais também vem diminuindo, como acontece com Mario Luzi, outro importante poeta da chamada Quarta Geração ${ }^{6}$, a quem, já nas vestes de prisioneiro, Sereni envia um postal em outubro de 1944:

Prisioneiro desde julho de 1943, rogo para que Emilia escreva a Maria Luisa Sereni - Felino di Parma - comunicando-lhe meu endereço e confortando-a sobre meu destino. Estou bem, espero ser seu companheiro em trabalho futuro. Lembranças de mim para todos. Me escreva ou peça para me escreverem. Um abraço. Vittorio Sereni. (LUZI; SERENI, 2017, p. 9)

O postal traz um selo sem data e na parte do remetente as seguintes informações: "Vittorio Sereni tenente 81-I-51461-R.E. nato USA prisioner of war enclousure F/6/126 Oran/Algerie". A preocupação de Sereni, como se lê, é assegurar um apoio à esposa Maria Luisa, que cuidava da filha Maria Teresa, nascida em julho de 1941, e Emilia é o nome da esposa de Mario Luzi. Depois de 25 de abril de 1945 ${ }^{7}$, data que marca a Liberação de todo o território italiano e que se torna um símbolo da luta partigiana, em 28 de junho, Luzi escreve a Sereni contando com o retorno em breve do amigo e afirmando que, apesar de saber que ele se sente mortificado, tem a certeza de

5 No texto L'anno Quarantatre (1963), Sereni recorda seu percurso desde Atenas, em que relembra do sorriso indefinível no rosto das pessoas da cidade, até a prisão e o campo de Chanzy: "Fui feito prisioneiro na Sicília, em Paceco (Trapani), por um batalhão aéreo-transportado do exército americano. Por volta das 13:30, do dia 24 de junho de 1943, na véspera da queda do regime. Há dois anos ou quase meu batalhão tentava chegar na África do Norte sem sucesso." (SERENI, 2013a, p. 904)

6 Quarta generazione também é o título de uma antologia organizada por Luciano D’Erba e Piero Chiara, publicada pela editora Magenta em 1954.

7 Em L'anno Quarantacinque, texto que integra o volume póstumo Gli immediati dintorni primi e secondi, de 1983, Sereni expressa como foi sua vivência dessa data tão importante para a história italiana mais recente: "Para nós não houve um verdadeiro 25 de abril ou, melhor dizendo, foi diluído ao longo de um período relativamente amplo que vai do final de julho de 1944 a maio de 1945 " (SERENI, 2013a, pp. 1065). Ou seja, todo o entusiasmo desse momento que também significava renovação não foi partilhado por Sereni. 
que aqueles anos não serão perdidos para ele, para a sua voz de poeta. No verão de 1945, Sereni retorna, enfim, à Itália e vai viver em Milão. A experiência desses fatos, que marcam a história e deixam cicatrizes indeléveis, é realmente incomum e até anômala. Enquanto uma boa parte de seus coetâneos participam de um modo ou de outro da liberação do território italiano, inclusive no papel de partigiani, como é o caso de Giorgio Caproni, na Valtrebbia, região da Ligúria, Sereni por uma série de contingências encontra-se distante de seu país, isolado num campo de prisioneiros, e não tem como compartilhar desse evento e dessa atmosfera.

A carta de Carlo Betocchi trazida no início desse ensaio foi escrita e enviada poucos meses antes que o destino de Sereni e sua participação na guerra fossem definidos e, portanto, antes da prisão pelos Aliados. Reler a carta, agora, depois das coordenadas dadas acima, significa refletir também sobre as expectativas individuais e coletivas, as esperanças colocadas no peso da farda, no desafio do dever para o qual se estava sendo chamado. A árdua superação das dúvidas, das hesitações mencionadas por Carlo Betocchi é um compromisso ao qual Sereni falta. Betocchi fala, obviamente, a partir da sua experiência, ou seja, do ponto de vista de um ex-combatente, que lutou e sobreviveu, por isso toda a simbologia do uniforme em suas palavras, da comunhão da "bela Itália", enfim, de um dever que se confunde com o viver. É o próprio Betocchi a comparar a forma com a qual ele se reporta a Sereni com a relação de intimidade entre pai e filho, relato, de certa forma, de uma experiência que agora se repete em outro momento e contexto. No final da carta, Betocchi reafirma ainda que é inegável a importância desse dever e, por conseguinte, dessa participação na primeira linha da história. Ora, contudo, pelo que foi exposto até aqui, o que acontece na singular e estranhante experiência de Vittorio Sereni é que esse sentimento de responsabilidade para com a "bela Itália", para com os demais, não se realiza em ações concretas durante a guerra. Não por uma sua recusa, devido às hesitações, aos medos, mas porque a prisão pelos Aliados o impede, é como se esse evento da prisão o suspendesse da história que se encontra em curso.

A peregrinação junto com a Divisão Pistoia, os deslocamentos entre Bolonha, Lubiana, Sicília e Argélia, está registrada nos textos reunidos em Gli immediati dintorni (1962), publicados na coleção Le Silerchie dirigida por Giacomo Debenedetti, que após a morte do poeta é reeditada com alguns acréscimos em 1983, mesmo ano da publicação de Senza l'onore delle armi, volume organizado por Dante Isella, cujo título é 
paradigmático por colocar em posição central a ausência da honra diante de uma derrota. Num dos textos desse volume, Le sabbie d'Algeria, é o próprio Vittorio que fala sobre esse destino desviante:

Estranho destino esse do meu ex-batalhão. Éramos gente do norte, na maioria emilianos, que há dois anos tentava chegar até o norte da África e não conseguia. Teríamos chegado lá, quem sabe como, in extremis e contanto que se passasse pelo Canal da Sicília, se um grande bombardeamento não tivesse destruído o aeroporto de Castelvetrano, em abril de 1943, na vigília do nosso embarque para a Tunísia. Fomos, então, destinados para a defesa das costas, e o nosso batalhão, equipado e armado para o norte da África, era como um departamento modelo diante das pobres desmoralizadas divisões costeiras. (SERENI, 1983, p. 251)

É com essas palavras que o poeta fala do "estranho destino" que irá marcar toda sua geografia existencial, de agora em diante. A condição peculiar de prisioneiro excluído da história tem uma consequência direta no sujeito, no mais íntimo "eu", na forma de se enunciar e se dizer. Tal condição é explicitada em vários textos e também no já citado L'anno Quarantacinque, quando Sereni relata as sensações no momento em que soube que a guerra havia acabado. "The war is over", é a frase ouvida que sentencia o fim do conflito, o próximo fim da prisão e acarreta uma reverberação interior, um tumulto de expectativas e apreensões que afloram diante do iminente retorno.

\begin{abstract}
A realidade infelizmente era mais modesta nas consequências imediatas, mas eu colocaria a esse ponto o início da fase final no que nos diz respeito e o início da nossa inércia morbosa, de uma terrível febre de egoísmo e impaciência, que diabo de imagem do futuro, que diabo de reconstrução da consciência, que diabo de retorno à responsabilidade e à ação [...] espiar no outro os sintomas daquele sofrimento e daquela febre do retorno, como os de um terrível mal que todos tivessem a consciência de terem sido atingidos e que todos queriam esconder diante de olhos alheios, último supérstite, agora única possibilidade, prova de virilidade... (SERENI, 2013a, p. 927)
\end{abstract}

E é, portanto, nesse sentido que se podem ler as palavras de Sereni ao dizer que há momentos da existência que enquanto permanecem informes não dão paz, e nisso também se encontra o significado da escrita e, sobretudo, dos versos. Não é possível não lembrar, então, do verso de um poema de Gli strumenti umani (1965), título emblemático para uma coletânea poética: "Fazem-se versos pra tirar um peso" (“Si fanno versi per scrollare um peso”, SERENI, 2013a, p. 197). A escrita como 
tentativa de um acerto de contas, cicatrizes em palavras que dão uma espécie de pele para a ferida, que continua ali, remarcada pela própria cicatriz.

Diario d'Algeria, publicado em 1947, pela editora Vallecchi, é mais do que um balanço da experiência como prisioneiro, traz o húmus de uma tragédia histórica vivida a partir da ausência. Em outras palavras, os poemas desse livro colocam no centro o estado de deriva, um estranhamento e um não saber. A ausência da história é dessa forma o tema fulcral, diante do qual o poeta não pode escapar e com o qual se sente impelido em fazer as contas.

O núcleo fundamental desse volume é o que pode ser chamado de o sentido de exclusão da história. Sereni basicamente se dá conta do fato de que, diferentemente dos demais coetâneos, não participou nem da guerra nem da Resistenza, que foram os dois grandes eventos entre 1940 e 1945. [...] Não participou, portanto, daquele momento, daquela atmosfera que era interpretada como um evento fundamental da história italiana. Excluído, assim, tanto de um fato quanto do outro.

A exclusão se torna, de fato, uma verdadeira chave para interpretar, para além do lado histórico, a própria existência como uma prisão. Nesse sentido, tentando ir um pouco mais adiante, torna-se ainda um modo para interpretar a vida como uma substancial prisão, como uma dimensão que vai bem além do dado histórico. A exclusão é sentida e percebida, enfim, como a característica da própria vida, como o enigma do não pertencimento a todos os movimentos, às realidades, às dinâmicas dos homens: o não se sentir, dito muito simplesmente, em casa na própria vida, na própria vida. (TESTA, 2016, p. 54)

Frontiera, livro que já apontava para aspectos relacionados a uma não pertença, a partir da própria geografia da cidade natal, traz um poema cujo desdobramento é central para se pensar a obra poética de Sereni, que toca a desassossegante presença dos mortos, que sofrerá com a guerra algumas variações. Trata-se de Strada di Creva, que é composto por dois fragmentos, sendo que o primeiro foi publicado primeiramente em revista. O título do poema fornece indicações concretas, uma estrada e um lugar chamado Creva, que fica nos arredores de Luino. Essa estrada também leva até o cemitério, daqui a abertura real e alegórica do título confirmada pelo segundo tempo do poema, que se abre com uma evocação dos mortos, vistos como inquietantes presenças familiares. "Esse perturbador viver dos mortos" (“Questo trepido vivere dei morti”, SERENI, 2013a, p. 88) é o verso inicial. De fato, os mortos não são mais apenas as presenças de certa pascoliana memória, mas podem ser também um estado entre os viventes humanos. A propósito desse texto, ainda, é 
relevante lembrar como Sereni no interior de sua própria obra, composta por apenas

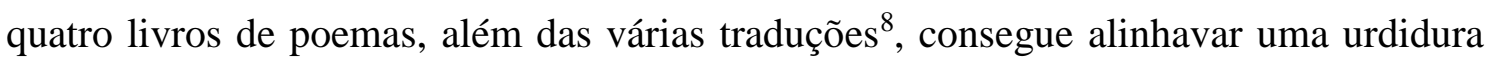
que poderia ser composta pelos seguintes textos que se auto-mencionam: Strada di Zenna e Strada di Creva, ambos de Frontiera, Ancora sulla strada di Zenna e Ancora sulla strada di Creva, de Gli strumenti umani, e Autostrada della Cisa, de seu último livro Stella variabile. ${ }^{9}$

Um dos nós, portanto, da urdidura de Diario d'Algeria é a morte, tanto do ponto de vista físico quanto daquele existencial. Morte que em outro poema é trazida por meio da imagem de uma flor, que é sempre imagem de vida e felicidade, porém, alerta o poeta, toda flor traz consigo a própria degeneração, não há flor que não expresse em seu próprio modo de existência a semente inerente a seu desaparecimento, isso é o que está exposto nos versos Diario bolognese. Esse sentimento aporético, que também pode ser lido a partir da dupla pertencimento e não-pertencimento, da perene e inquietante dúvida ${ }^{10}$, nunca será abandonada pelo poeta: o que se percebe é um desdobramento desse sentimento que inclusive chega a desestabilizar e corroer o "eu" e a própria linguagem, ou nas palavras de Franco Fortini, "o sentido da própria fugacidade" (FORTINI, 2003, p. 579).

É em julho de 1940 que a Itália rompe a neutralidade e entra no conflito bélico ao lado da Alemanha de Hitler. A passagem de uma vida de paz para uma vida incerta, marcada pela guerra, é central para a leitura do poema colocado não casualmente na abertura de Diario d'Algeria:

\section{Periferia 1940}
A juventude está toda na luz de uma cidade ao entardecer onde lacerado e êxule todo som se sobressai do ruído.
E tu minha vida podendo te salves te conserves para o futuro

\footnotetext{
8 Vittorio Sereni como outros escritores de sua geração tem uma intensa atividade como crítico e tradutor, no caso específico de Julien Green, Paul Valéry, William Carlos Williams, René Char, Guillaume Apollinaire.

9 Sobre essa relação entre os poemas, ver parte do ensaio PETERLE, 2015, pp. 40-43.

10 A dúvida como já foi colocado por alguns críticos, TESTA, 2016, MENGALDO 1975, GHIDINELLI, 1999, é inclusive indicada sintaticamente por meio tanto por meio da modalidade da repetição e do uso feito da conjunção adversativa "ma" [mas].
} 
Fênix - Revista de História e Estudos Culturais

Janeiro - Junho de 2021 Vol.18 Ano XVIII no 1 ISSN: $1807-6971$

Disponível em: www.revistafenix.pro.br

passante e as aparências nas pontes

no reluzir dos faróis

(SERENI, 2013a, p. 243)

Como diz o primeiro verso, a juventude encontra-se toda na luz da cidade, contudo a hora escolhida pelo poeta não é a potente e crescente da manhã presente nos versos escritos no fronte da primeira guerra por Giuseppe Ungaretti ${ }^{11}$, mas sim aquela do pôr-do-sol, momento em que a luz perde sua intensidade, antes de entrar na escuridão da noite. $\mathrm{O}$ ruído presente nos últimos dois versos dessa estrofe talvez ecoe um dos motetos de Montale de Ocasiões (1939), em que um ruído vindo do aberto, ou seja do fora, dá a sensação de arranhar como uma unha os vidros. Som, certamente, que expressa uma agonia e que pré-anuncia o verso final do moteto: "E é certo o inferno" (MONTALE, 1997, p. 57). ${ }^{12}$

Giorgio Caproni, outro poeta muito ligado a Montale e amigo de Sereni ${ }^{13}$, num poema intitulado 1944, de A passagem de Enéas (1956), também não sente a necessidade de usar o termo inferno, por ser talvez uma redundância e uma quebra da atmosfera infernal por ambos perfilada, já trazida nos versos. Esse poema caproniano, 1944, coincidentemente, também traz a imagem do sol. Dois poemas, então, de atmosfera bélica, um escrito no início da guerra e outro mais para o final do conflito, que desconstroem o imaginário acolhedor evocado a partir de "sol". Imaginário que carrega consigo toda uma tradição poética e uma relação com a natureza que é, agora, rompida pelo evento devastador.

\section{4}

As carroças do leite ai enquanto o sol já quase espeta os cães. O que ensaca a morte sobre o sílex no fragor das garrafas que balançam? No rosto já punge a folha do primeiro jornal com sua acridez de chumbo - imensa água passa deserta no sangue a quem a um muro

11 A referência é aos versos do poema Manhã, que foram traduzidos por Haroldo de Campos: "Deslumbro-me / de imenso" (WATAGHIN, 2003, p. 57)

12 Na tradução de Geraldo Holanda Cavalcanti, a escolha para traduzir a indicação de onde vem o ruído, que em italiano é "aperto", foi "espaço". Mantive na análise a referência ao aberto por ser um termo que tem um peso maior tanto no poema quanto para uma reflexão que pode também vir da filosofia.

13 A relação de amizade entre Giorgio Caproni e Vittorio e Sereni é tão intensa que fica, inclusive, registrada nos versos dos dois poetas e também nas dedicatórias dos livros presenteados. Ver PETERLE, 2020b. 
Fênix - Revista de História e Estudos Culturais

Janeiro - Junho de 2021 Vol.18 Ano XVIII no 1 ISSN: $1807-6971$

Disponível em: www.revistafenix.pro.br

encosta, e já a descarga uma lata

entre os cacos se abala. Oh amor, amor

que desastre é a alvorada! Dos portões

onde a primeira chave geme, oh amor

não fuja com o último tepor

noturno - não escanda esses sons

que aos meus dentes seu trêmito impõe.

(CAPRONI, 2012, p. 107)

O poema de Giorgio Caproni marca o tempo no verso inicial por meio da imagem da carroça de leite, ou seja, está-se no amanhecer do dia, quando ainda o leite chegava cedinho nas casas em garrafas de vidro. Outro elemento é a folha do primeiro jornal, caracterizada com "acridez de chumbo", chumbo que se refere tanto à tinta da impressão do jornal quanto ao chumbo relacionado às armas, como confirmam logo depois os termos "sangue" e "muro". Caproni nesse poema fala dos fuzilamentos, escutados e executados pela manhã, o barulho de uma lata que vibrava (CAPRONI, 2004). Nota-se que o contato com sol não é agradável, ele "espeta", não acaricia ou aquece como seria o esperado, e, da mesma forma, o jornal "punge”. É Pier Paolo Pasolini, em Passione e ideologia ${ }^{14}$ (1960), que chama a atenção para o uso das interjeições que permeiam essa tessitura de pathos e que apontam para a complexidade da operação de figuração da realidade, cortada pelos sobressaltos e ruídos também estridentes das garrafas de leite. A imagem final é o bater dos dentes por toda a sensação de ameaça e medo, o falar de dentro do inferno.

Retomando Periferia 1940 de Sereni, a segunda estrofe pode ser lida como uma espécie de presságio. Mas o que chama mais a atenção é que aqui há um descolamento do "eu" do poeta e da possível vida, a quem ele se dirige com um "tu", como se a vida pudesse escutar seu pedido-prece para se salvar. Escavando, encontramse talvez outros ecos montalianos, agora de Ossos de sépia (1925), nessa segunda parte do texto: "Minha vida, a ti não peço traços / firmes, ares plausíveis ou de posse. / No teu giro inquieto já o mesmo / sabor têm o mel e a losna" (MONTALE, 2001, p. 75). Mel e absinto. Vida e morte, o amanhã sem estações - sem a ritualidade e a renovação que elas invocam.

O sentimento de inermidade é, de fato, o que está presente em outro emblemático poema em cujos versos essa condição é mais uma vez expressa. Italiano in

14 Volume que reúne vários textos críticos de Pasolini dedicados à poesia, entre eles a resenha dedicada a Giorgio Caproni que foi publicada primeiramente em 1952, na revista Paragone. 
Grecia - datado Pireu, agosto 1942 -, de Diario de Algeria traz em seus versos: "Europa Europa que me olhas /descer inerme e absorto em um meu / êxile mito entre as tropas dos vis" ("Europa Europa che mi guardi / scendere inerme e assorto in un mio / esile mito tra le schiere dei bruti”, SERENI, 2013, p. 111). Aqui tem-se uma Europa nas vestes de mãe trágica e o pranto de um "eu" que é acentuado pelos enjambements. A descida faz referência à viagem, mencionada no início do ensaio, da Divisão Pistoia até a Grécia, à participação no conflito, o inimigo aqui é o próprio sentimento de tristeza que toma conta do "eu" e que se concretiza no verso final quando é deflagrada a condição infernal, "vou me danar me encalhar por anos" ("vado a dannarmi a insabbiarmi per anni”, SERENI, 2013, p. 111). Não há nenhuma perspectiva metafísica, é o hic et nunc, é o duro embate com essa realidade que arde, queima, corrói, como aponta Giorgio Caproni ao resenhar a segunda edição de Diario d'Algeria ${ }^{15}$, publicada em 1965 pela Mondadori. Na resenha para La Nazione, de 16 de novembro, ele faz balanço sobre a escrita de sua geração, e se questiona se depois de ter "saído do inferno", "teria conseguido do fogo, a nossa fênix árabe ressurgir nova e única na substância?" (CAPRONI, 2017, p. 228). A resposta oferecida por Caproni é certeira:

Sereni que voltou vivo dos padecimentos da guerra e da prisão, sem renegar nada de si mesmo, havia reagido aos "fatos" do único modo permitido a um homem digno de viver. Havia encontrado no fundo do próprio desespero, e sempre fiel a este, a voz mais propícia para registrar e comunicar os fatos e seus ecos despertados no coração. Um coração não preocupado somente consigo, mas sobretudo com toda a Europa e uma inteira civilização, um inteiro patrimônio - doloroso até o espasmo, mas humildemente exaltante - de "história" comum. [...] E a recuperação não era um impossível ponto e um recomeço, mas um continuar, segundo o continuar dos eventos e o crescer (o somar) da experiência e da própria vida. (CAPRONI, 2017, p. 228)

A corrosão atinge a filigrana mais sutil do sujeito, que se sente desalojado inclusive de si mesmo, e a dimensão onírica, o a-lógico, torna-se, assim, uma via, ou melhor, uma exigência como se lê em outros versos datados "Campo Hospital 127, junho 1944", que começam com "Não sabe mais nada" ("Non sa più nulla", SERENI, 2013, p. 124). A esfera onírica domina a primeira estrofe desse outro texto do Diario,

15 Essa edição de Diario d'Algeria não traz relevantes mudanças no que diz respeito a variantes textuais, contudo no que diz respeito à estrutura do livro há alterações significativas, como a supressão das duas últimas seções e a inserção de uma intitulada Il male d'Africa, composta por poemas intervalados com prosas escritas depois do retorno da guerra. 
em que a voz murmurante (música bizarra provocada pelo vento) de um soldado morto na praia pede para que o "eu" continue rezando pelo destino da Europa, enquanto a Nova Armada desembarca na Normandia (6 de junho de 1944). A resposta dada a esse pedido, se aquela voz é realmente a de um soldado morto na praia da Normandia, é que ele reze, se puder, porque:

\author{
[...] eu estou morto \\ para a paz e para a guerra \\ Agora essa é música: \\ das cortinas que batem nos postes. \\ Não é música da anjos, é a minha \\ única e me basta -.
}

(SERENI, 2013a, p. 124)

A morte em vida é deflagrada nesses versos, condição do "eu" sereniano que passa a ser estendida montalianamente a todos aqueles que continuam buscando no céu os antigos sinais, os falsos emblemas. Eles, diz Sereni ainda em outro poema, sempre de Diario d'Algeria, não sabem que estão mortos, mortos como nós, que não têm paz.

\title{
II
}

\author{
Vocês mortos não nos dão nunca paz \\ (Strada di Zenna, Vittorio Sereni)
}

Num determinado momento da visita em Luino, Vittorio nos levou ao cemitério, e ali na sepultura da família, ao lado dos outros espaços já ocupados, nos indicou com um breve gesto o vazio na espera do seu. Não esquecerei aquela tocante prova de amizade, aquele gesto. E hoje, mais do que pensar no corpo encolhido e fechado entre aqueles de seus mortos, quero lembrar o gesto pacato e quase sem tristeza de quem não temeu viver a vida inteira em companhia dos mortos e da morte.

(Ricordo di Vittorio Sereni, Pier Vincenzo Mengaldo)

O estalido já imperceptível da combustão, o tempo farfalhante dos fornos, o sentimento de culpa por ter sobrevivido são imagens que retornam anos depois em 
outros escritos, como no conto L'opzione ${ }^{16}$, publicado no número 8 da revista Questo e altro. A experiência da guerra e o sentimento de exílio e exclusão não são apagados, mesmo depois de algumas décadas, como é corroborado tanto nos escritos em prosa como nas duas últimas coletâneas poéticas, Gli strumenti umani (1965) e Stella variabile (1975). O que acontece é que outras camadas, outras concreções vão se formando, inclusive com a mudança que a sociedade italiana vai sofrendo. A partir da década de 1950 a modernização e a industrialização aceleradas, que continuam nos anos 60, transformam a sociedade italiana, como mais tarde irá deflagrar na crítica pungente e implacável de Pier Paolo Pasolini. O boom econômico, a aceleração e a maciça entrada no capitalismo mudam o modo de ser, a forma de vida, como bem indica a expressão pasoliniana, "mutação antropológica", que não deixa de ser uma dolorosa consciência que o poeta, crítico e cineasta vinha elaborando nos últimos anos de sua vida $1974-75 .^{17}$

Transformações operantes a partir da esfera inclusão-exclusão, como aponta Roberto Esposito em O pensamento vivo (2013), ao refletir sobre a mudança estratégica do poder capitalista, que passa de uma lógica de exclusão à de inclusão, ou, melhor dizendo, da perfeita sobreposição em um dispositivo de inclusão excludente. Pasolini chegará inclusive a falar de um "genocídio sem sangue". É, portanto, nesse contexto de uma Itália economicamente recuperada do pós-guerra, em plena transformação, que se insere um segundo momento da produção de Sereni, cuja trajetória no mercado de trabalho desses anos é mais um sintoma das mudanças radicais. Em 1958, depois do ensinamento escolar e da experiência na assessoria de imprensa e propaganda de uma grande fábrica como a Pirelli, Sereni se torna diretor literário da editora Mondadori, cargo que ocupa até 1975, ano de publicação de seu último livro, Stella variabile. O conto L'opzione, e também Il sabato tedesco, que pode ser lido como uma continuação do primeiro, é fruto de viagens realizadas pelo poeta-diretor à célebre Feira do Livro, que se realiza todo ano em Frankfurt, para negociar e comprar direitos de livros.

16 Outro conto importante é Il sabato tedesco, que é uma espécie de continuação escrita com a distância de vinte anos.

17 A elaboração da reflexão a respeito da "mutação antropológica" pode ser acompanhada nos escritos de Pasolini para os principais jornais da época, textos que mais tarde foram reunidos em Lettere Luterane (1976) e Scritti corsari (1975), mas que também não deixam de estar presentes em Salò ou os 120 dias de Sodoma (1975) e no romance inacabado Petrolio, publicado póstumo em 1992. 
Em L'opzione, tem-se um personagem formado em Letras que acaba trabalhando no mundo da indústria, mas que, não se reconhecendo nesse ambiente, se sente deslocado, como alguém que está fora de seu lugar. A experiência autobiográfica é claramente inevitável, mas esse conto não pode se limitar a essa dimensão, uma vez que faz parte de um amplo debate que marca os primeiros anos da década de 60. Esse conto, de fato, também como Intermezzo neocapitalistico, insere-se no efervescente debate sobre indústria e literatura, que já havia sido trazido à público em 1961, no quarto número da revista Menabò, dirigida por Elio Vittorini ${ }^{18}$ e Italo Calvino, com textos que tratavam dessa complexa relação. Esse número da revista contou com uma seleção de poemas de Giovanni Giudici, intitulada Se sia opportuno trasferirsi in campagna, com o Taccuino industriale de Ottiero Ottieri, com L'uomo di qualità de Lamberto Pignotti, entre outros, e também com a participação do próprio Sereni com o emblemático poema Una visita in fabbrica que ocupa uma posição central em Gli strumenti umani. Contudo não é a primeira vez que os textos publicados em Menabò tratavam dessa relação: o segundo número da revista, em 1960, de fato, traz na íntegra o famoso poema em polímetro La ragazza Carla, de Elio Pagliarani, cheio de traços realistas e experimentações linguísticas. É a história de Carla Dondi, de 17 anos, moradora da periferia de Milão (Viale Ripamonti), entre o outono de 1947 e a primavera de 1948, quando ela faz um curso de datilografia e começa a trabalhar numa empresa de import-export. ${ }^{19}$ Outros nomes importantes que também tocaram nesse tema e contribuíram para esse debate são os de Goffredo Parise, Paolo Volponi e Luciana Bianciardi.

L'opzione de Sereni, então, pode ser inserido nessa reflexão entre literatura e indústria ou literatura e mercado, mas é interessante também destacar outro aspecto que diz respeito a uma reflexão metaliterária que é feita nessas páginas e que, por sua vez, se relaciona com a problematização acerca da expressão da experiência, ou seja, se literatura e linguagem são capazes de expressá-la.

18 O papel intelectual de Elio Vittorini é fundamental nesses anos. Ele também foi diretor da importante revista Il politecnico logo depois da guerra, que publicou seus números entre setembro de 1945 e dezembro d 1947. É nessa revista que Sereni, em 1946, publica alguns poemas que depois farão parte de Diario d'Algeria. Sobre Il Politecnico ver PINTO, 2019.

19 Cf. GHISI; CARMINATI, 2020. 
Fênix - Revista de História e Estudos Culturais

Janeiro - Junho de 2021 Vol.18 Ano XVIII no 1 ISSN: $1807-6971$

Disponível em: www.revistafenix.pro.br

Todo voltado como era para formar mais do que expressar ou representar, obcecado como era pela circularidade e simultaneidade dos gestos, grandes e pequenos, da existência, devia evitar aqueles pensamentos, aquelas suspensões, aquelas voltas emotivas, aquelas intrusões que, mais espertos do que a caneta ou a tecla typewriting, são depósitos instantâneos produzindo a calosidade do instante e os mofos do presente - o qual, como já se sabe universalmente, no momento em que você o sente e o nomeia ele já passou. Ainda mais nos nossos tempos, ainda mais. (SERENI, 2013a, p. 1081)

De fato, as páginas de L'opzione podem ser vistas como um "falatório" de diferentes vozes, diversas línguas que fazem parte do contexto e das tratativas de compra-venda da Feira, com algumas pitadas oníricas. O fragmento acima, retirado da parte final do texto, traz o momento em que o escritor-personagem do texto reflete sobre o elo entre escrita e temporalidade, em que o presente é visto como a dimensão em que as coisas acontecem, como a esfera da experiência: "como já se sabe universalmente, no momento em que você o sente e o nomeia ele já passou". A questão posta por Blanchot em A literatura e o direito à morte está posta aqui também por Sereni, o sentimento de exclusão é agora também vivido e sentido por dentro do processo de escrita, da experiência com a linguagem, que quando tenta nomear perde a coisa. Nesse sentido, é interessante lembrar as palavras com as quais o próprio Sereni se refere a L'opzione, que chamamos aqui de conto. Para ele, de fato, L'opzione não é visto como um conto, mas também não é uma prosa, nem poesia, nem um policial, é "uma coisa", "um organismo vivo", como ele mesmo escreve ao editor Scheiwiller. A reflexão sobre a linguagem, sobre sua capacidade de representação do real e, por conseguinte, de nomeação é uma questão que atravessa o século XX, de Blanchot a Foucault, a Caproni, a Sereni, a Celati. ${ }^{20}$

Talvez seja também por isso que na introdução ao volume La tentazione della prosa, publicada póstuma em 1998, Giovanni Raboni, além de chamar a atenção para a fluidez rítmica e sintática e para os traços metafóricos e alegóricos dessa prosa, afirma que L 'opzione é:

uma compacta pequena, cintilante obra-prima em que o antigo prazer do romance de criar com palavras uma realidade vivível com curiosidade e emoção em todo seu atraso descritivo e em toda sua dobra de sentido é continuamente infiltrado, exaltado e transfigurado por uma tensão espasmódica até a dor e, todavia, sutilmente,

20 Cf. PETERLE; SANTURBANO, 2020. 
Fênix - Revista de História e Estudos Culturais

Janeiro - Junho de 2021 Vol.18 Ano XVIII no 1 ISSN: $1807-6971$

Disponível em: www.revistafenix.pro.br

deliciosamente exilarante na direção de um significado geral e transcendente, uma misteriosa, contudo, reluzente alegoria. (1998, p. XVII)

A incancelável recordação da guerra e das tragédias do século, como aponta Enrico Testa em sua premissa a Cinzas do século $X X$, que traz dois importantes ensaios dedicados a Vittorio Sereni e Giorgio Caproni, se materializam na escrita desses poetas mediante indícios de "desmoronamento geral dos alicerces tradicionais do estar no mundo, que envolve a sistematização da linguagem, o estatuto da identidade, com sua redução a "passante" ou a "além-morto", e as fundamentais coordenadas de espaço tempo e experiência." (TESTA, 2016, p. 20). De fato, se para o primeiro a problematização da identidade - considerando a condição de morto-vivo-morto - se torna um aspecto central de seu fazer poético, que está relacionado com a questão acima trazida em L'opzione, ou seja, a "a relação entre as coisas e as palavras, entre a linguagem e os dados da realidade" (TESTA, 2016, p. 31), para o segundo é a problematização e a investigação sobre o mal - a res amissa - o vórtice inextricável em que ele se embrenha. É talvez com essas coordenadas que se pode ler outro fragmento da já mencionada resenha de Caproni de 1965:

Esvaziados no vazio de seus próprios discursos, os primeiros agitados porta-bandeiras vexilários da 'poesia social', uma outra perturbação bem diferente entrou, desta vez com fins demasiados metódicos, recheada de novos humores e de novas descobertas e formulações, na organização de uma nova sociedade e de uma nova cultura que, levadas por uma real necessidade, mas talvez mais narcisisticamente apaixonadas pelas próprias buscas do que verdadeiramente aterrorizadas, iam e ainda vão procurando interpretar e resolver a nova tragédia que se juntou àquela da arbitrariedade e da guerra. A tragédia, enfim, da incapacidade de reencontrar uma humanidade concreta e profunda no próprio bem-estar e na mordaça da industrialização que a produziu, e de poder chegar a uma escolha definitiva entre os supérstites sobreviventes? alternativos do passado e os já também gastos do presente. (CAPRONI, 2017, p. 229)

Tragédia que se lê também em Ritorno dalla notte, escrito em 1964, que não deixa de remeter ao tríptico Dall'Olanda ${ }^{21}$ presente em Gli strumenti umani - que evoca a história de Ana Frank - e ao já mencionado L'opzione. É possível lembrar nesse sentido a relação com Paul Celan, lembrada por Sereni em outros textos, inclusive

21 Uma detalhada análise do fragmento sereniano, que traz a figura de Ana Frank, encontra-se em TESTA, 2016, pp. 66-72, ver também MENGALDO, 1972. 
cintando Claudio Magris, que trazem a tensão presente na relação com a língua. Celan, que se suicida jogando-se no rio Sena em 16 de abril de 1970, nasce como Paul Antschel, em Cernovitz, de pais judeus de língua alemã, ou seja, a mesma língua dos assassinos de sua mãe, os nazistas. Sereni nessas incursões e em seus gestos poéticos aponta para seu olhar antropológico, inerente à escrita, evidenciando que a origem do monstruoso não está distante, mas está no fato que foram homens e nada mais do que homens os sujeitos e os objetos de todo evento, não foi uma mente fora dessa terra, desse mundo, foi uma mente indiscutivelmente humana. E continua Sereni,

Uma análise mais fria leva a considerar a organização, a regra com a qual se colocava a mão na construção de um mundo uniforme, atemporal, sub-humano: uma espécie de hipótese atroz de uma "nova" forma de vida sem indivíduos, quase uma paródia antecipada - e, por sua vez, atroz - de uma sociedade sem classes. (SERENI, 2013a, p. 1499)

Palavras, essas, que podem remeter a um contexto muito diferente e à leitura de um dos poemas mais famosos de Vittorio Sereni, publicado em Gli strumenti umani, em que são estabelecidas correlações entre o espaço da fábrica e o do campo de concentração, Una visita in fabbrica. Ele toca sem dúvida alguma no tema do trabalho na fábrica de forma muito original. Uma vez que ele não se limita a descrever de fora os sofrimentos ou a vida dos operários, mas dá voz àqueles que ocupam esse espaço, fazendo com que o ponto de vista deles apareça. O poema é formado por 95 versos, divididos em cinco partes e é o segundo texto mais longo do livro. Logo abaixo do título há uma data, 1952-58, mas se sabe que ela não se refere à escrita do texto, que parece ter sido terminado em 16 de abril de 1961, como aponta Dante Isella nos comentários críticos da edição Poesie. Nas primeiras duas partes do poema, é apresentada a situação inicial, um grupo de pessoas, entre as quais está o próprio Sereni, que chega para, justamente, visitar uma fábrica. ${ }^{22} \mathrm{Na}$ terceira parte, Sereni se dirige e faz perguntas diretamente aos operários. Na quarta, é a vez de um operário tomar a palavra e falar do seu ponto de vista. Enfim, chega-se na quinta e última parte. A fábrica nesse emblemático poema é um lugar de infortúnios de sofrimento, de morte. A dor contida e

22 Visita que realmente aconteceu como Sereni descreve em Angelo in fabbrica, datado de 1958 (SERENI, 2013, p. 612). Nesse texto, ele fala de uma pessoa combativa, L., conhecida no passado, que havia participado da Resistenza, uma mulher com um sobretudo e uma metralhadora na mão, mas que agora aparece "docilizada", "domesticada", obedecendo às ordens de seu chefe dentro da fábrica. 
Disponível em: www.revistafenix.pro.br

sentida nesse espaço chega a lembrar a dor da guerra, até o ponto de a fábrica parecer um campo que não deixa nenhuma esperança a suas vítimas, impedindo-as de ter consciência das próprias condições. Os ritmos neuróticos do trabalho ameaçam as próprias relações humanas, tratando-se de um poder disciplinar, como bem apontou Foucault em seus estudos sobre a progressiva utilização dos dispositivos disciplinares que atua no corpo. Os operários são mão de obra economicamente útil e politicamente dócil: "É dócil um corpo que pode ser submetido, que pode ser utilizado, que pode ser transformado e aperfeiçoado" (FOUCAULT, 2008, p. 118). A relação entre docilidadeutilidade é a que move esse espaço, uma espécie de cidadela fechada, com guardiões que abrem e fecham os portões e gerenciam as demandas. Ou, como aponta Hannah Arendt em A condição humana,

A era moderna trouxe a glorificação técnica do trabalho, e resultou na transformação efetiva de toda a sociedade em uma sociedade operária. Assim, a realização do desejo, como sucede nos contos de fadas, chega num instante em que só pode ser contraproducente. A sociedade que está para ser libertada dos grilhões do trabalho é uma sociedade de trabalhadores, uma sociedade que já não conhece aquelas outras atividades superiores e mais importantes em benefício das quais valeria a pena conquistar a liberdade. (ARENDT, 2007, p. 12)

Os dispositivos e as formas disciplinares existentes no interior de uma fábrica, a quantidade de produtos a serem acabados, o toque infernal das sirenes que penetra no corpo e que passa a marcar a cadência do tempo, de chronos, do progresso são os elementos lidos por Sereni nesse poema. Não é, então, uma coincidência que o poema traga logo nos primeiros versos os termos "grito", "sirene" e fábrica": "Alegremente no ar de setembro mais sibilo que grito / longínqua uma sirene de fábrica" ("Lietamente nell'aria di settembre più sibilo che grido / lontanissima una sirena di fabbrica", SERENI, 2013, p. 288). Porém, no final da primeira parte, tem-se sintomas de mudança, uma vez que o ar já não é mais perfilado pelo advérbio "alegremente", mas passa a ser acompanhado pelos adjetivos "amargo" e "vazio". ${ }^{23}$ Tal mudança segue corroborada

23 Os versos são os seguintes: "No amargo e vazio uma larva do som / das sirenes desligadas, não mais uma voz / mas os breves frêmitos em ondas sempre mais lentas / um aroma de mistura num cheiro de sangue e cansaço". Nota-se como pouco a pouco a atmosfera da fábrica vai se entrecruzando com aquela da guerra. O cheiro de sangue é um elemento em comum entre elas. Os textos literários e críticos sobre esse argumento são inúmeros, mas gostaria de registrar aqui o poema Zona vermelha de Maria Grazia Calandrone, escrito em março de 2020, em meio à primeira onda da pandemia, que traz para o primeiro plano a figura de uma operária nomeada com "N." numa fábrica da região da 
pelo som da sirene que não é mais trazido como um sibilo, mas aparece agora por meio da imagem de uma "larva do som / das sirenes desligadas". Memória individual, coletiva e histórica se entrecruzam nesse poema, além de uma densa rede intertextual que perpassa pela tradição literária, de Dante a Montale. ${ }^{24}$

Rumor... rumor de maquinários que se sobrepõem às vozes trabalhadoras silenciadas pela sirene, relegadas a um "filo di benessere". Um movimento estranho para o olhar do poeta, uma sensação de estranhamento perturbadora, que ao mesmo tempo em que se sente distante é "atraído" e captado pelo ritmo da atmosfera desoladora. $\mathrm{O}$ estranhamento dominante das primeiras imagens faz com que o poeta saiba que ele não conhece aquele "sotto terra" e, por isso, é necessário prestar atenção na "voce degli altri" e no "suono del buio della mente". (PETERLE, 2015, p.48)

Ou, nas palavras de Foucault, lentamente uma coação calculada percorre cada parte do corpo, se assenhoreia dele. Dobra o conjunto, torna-o perpetuamente disponível, e se prolonga, em silêncio, no automatismo dos hábitos; em resumo, "foi expulso o camponês" e lhe foi dada a "fisionomia de soldado" (FOUCAULT, 2008, p. 118). Esses operários não seriam também mortos-vivos? Há também nesse espaço moderno uma exclusão da vida, da vida social e, sobretudo, de si. A reflexão e a experiência do presente exigem e recorrem à memória em Sereni. A lembrança nessa escrita possui tanto uma natureza individual, particular, quanto uma mais coletiva, e é essa tensão que se abre no presente anacrônico e permite ao poeta falar sobre o trauma vivido, inclusive a partir de figuras como Ana Frank, Primo Levi e Paul Celan, que Sereni traz em diferentes momentos de seus textos poéticos, contos e outros de caráter ensaístico. Presenças que se unem àquela dos outros tantos mortos que povoam sua escrita e que, por isso mesmo, ainda vivem. Os mortos são, como se lê em La spiaggia, que poderia dialogar com o poema trazido de Diario d'Algeria, não aquilo que é desperdiçado, mas "remendos de existências", ruinas para falar benjaminiamente, “cinzas", que podem a qualquer momento jogar uma luz. A poesia se torna, portanto, a possibilidade de um contato, de uma relação e de um encontro com o passado e com o fluxo inexorável do presente.

Lombardia. O poema foi lido pela poeta no vídeo para o projeto Krisis - Tempos de Covid-19, sendo depois esse texto, junto com outros, publicado em livro.

24 Cf. KUTUFÀ, 2020; PETERLE, 2015. 
A arte e, especialmente, a poesia são um meio - um gesto - que, mesmo transformando, conseguem acenar e, de algum modo, manter relações. É, se quisermos, uma relação a partir da própria impossibilidade de relação que é dada pelo acontecimento da morte, que passa a ser revisitado e refigurado. Nesse sentido, a palavra mais do que ressuscitar, tenta atrasar a força avassaladora do tempo, que empurra rumo ao esquecimento. As palavras em suas combinações trazem ecos longínquos, tesselas de um mosaico que por sua natureza será sempre incompleto, o tranquilo desespero kierkegaardiano. $\mathrm{O}$ emudecimento é necessário, da mesma forma que a linguagem também o é, se tornando um espaço de exposição da relação, de suas singularidades. A falta se torna voz, talvez balbuciante e trêmula, pois expõe nesse processo seus próprios limites. (PETERLE, 2020, pp. 182-183)

\section{POST SCRIPTUM}

Enquanto estava sendo finalizada a escrita desse ensaio, numa pequena cidade balneária da Liguria, Camogli, no dia 24 de fevereiro, uma parte do cemitério, edificada em cima de um penhasco, como acontece com muitas das construções dessa região paisagens e atmosferas delineadas no Cemitério Marinho de Valéry -, desmoronou, misturando terra, rocha, caixões, restos mortais nas águas do mar lígure. Alguns dos restos mortais foram repescados recuperados? junto com pedaços de caixões, mas os trabalhos de resgate continuam enquanto as gaivotas, seguindo seu instinto, aproveitam da "fartura" nas águas. Foram os operários que estavam trabalhando nas obras de reestruturação do cemitério que ouviram, viram e inclusive chegaram a gravar alguns vídeos armadores. Para além da discussão da manutenção dos espaços públicos e dos inúmeros descasos dos governos, gostaria, então, de finalizar com uma reflexão que toca a nossa contemporaneidade, a partir também do percurso sugerido pela poesia de Sereni. Os restos das construções do cemitério, humanos, agora também falam. Falam por meio de um desastre também natural. Falam uma outra língua, como a da natureza que nada desperdiça, que se autorregula; os restos mortais no mar lígure se transformam em vida nesse ataque predatório das gaivotas. Por caminhos muito diversos, chega-se ao embate com uma questão que atravessou o ano de 2020, com as milhares de mortes causadas pela pandemia de covid-19. Gostaria de concluir, portanto, com os emblemáticos últimos versos de La spiaggia, que encerra Gli strumenti umani:

Não, duvide, - me dá um pouco da sua força o mar- 


\section{REFERÊNCIAS BIBLIOGRÁFICAS}

ANCESCHI, Luciano. Lirici nuovi. Milano: Hoepli, 1943.

ARENDT, Hannah. A condição humana. Trad. Roberto Raposo, posf. Celso Lafer. Rio de Janeiro: Forense Universitária, 2007.

CAPRONI, Giorgio. A coisa perdida. Agamben comenta Caproni. Trad. Aurora Fornoni Bernardini. Florianópolis: Ed. da UFSC, 2012.

ESPOSITO, Roberto. O pensamento vivo. Trad. Henrique Burigo. Belo Horizonte: Editora UGMG, 2013.

ESPOSITO, Edoardo. Lettura della poesia di Vittorio Sereni. Milano: Mimesis, 2015.

ESPOSITO, Edoardo (Org.). Vittorio Sereni, un altro compleanno. Milano: Ledizioni, 2016.

FORTINI, Franco. Saggi ed epigrammi. Org. Luca Lenzini, pref. Rossana Rossanda. Milano: Mondadori, 2003.

GHIDINELLI, Stefano. 'L'infaticabile 'ma' di Sereni. In Studi Novecenteschi, v. 26, n. 57, jun, 1999, pp. 157-184.

GHISI, Agnes. CARMINATI, Helena Bressan.Entre prosa e poesia: o experimentalismo de Elio Pagliarani. In Literatura Italiana Traduzida, v.1., n.2, fev. 2020.Disponível em https://repositorio.ufsc.br/handle/123456789/209952 . Acesso em 15.02.2021.

FOUCAULT, Michel. Microfísica do poder. Org., introd. de Roberto Machado. Rio de Janeiro: Paz e Terra, 2017.

FOUCAULT, Michel. Vigiar e punir: nascimento da prisão. Rio de Janeiro: Vozes, 2008 .

KUTUFÀ, Paolo. "Raffrontando e / rammemorando", memoria e alegoria in Una visita in fabbrica di Vittorio Sereni. In L'ospite ingrato, n. 7, 2020. Disponivel em https://www.ospiteingrato.unisi.it/raffrontando-e-rammemorandomemoria-e-allegoriain-una-visita-in-fabbrica-di-vittorio-serenipaolo-kutufa/ . Acesso em 5.02.2020.

MENGALDO, Pier Vicenzo. "Iterazione e specularità in Sereni”. In Strumenti critici, n. 17, 1972, pp. 19-48. 
MONTALE, Eugenio. Poesias. Trad. Geraldo Holanda Cavalcanti, pref. Luciana Stegagno Picchio. Rio de Janeiro: Record, 1997.

MONTALE, Eugenio. Ossos de sépia. Trad. Renato Xavier. São Paulo: Companhia das Letras, 2001.

PASOLINI, Pier Paolo. Passione e ideologia. Milano: Garzanti, 1960, pp. 424-428.

PETERLE, Patricia. No limite da palavra. Rio de Janeiro: 7Letras, 2015.

PETERLE, Patricia; GASPARI, Silvana de. Itália do pós-guerra em diálogo. Rio de Janeiro: Comunità, 2012.

PETERLE, Patricia; SANTURBANO, Andrea (orgs.). Contemporaneidades na/da literatura italiana. Florianópolis: Rafael Copetti Editor, 2020.

PETERLE, Patricia. "Contatos necessários: uma reflexão sobre a tradução de "A toalha" de Giovanni Pascoli. In Aletria: Revista de Estudos de Literatura, n. 30 (4), 2020a, pp. 177-199.

PETERLE, Patricia. "O silêncio criativo": sobre a poesia de Vittorio Sereni". In Literatura Italiana Traduzida, v.1., n.7, jul. 2020b. Disponível em https://repositorio.ufsc.br/handle/123456789/209578 . Acesso em 30.01.2021.

PETERLE, Patricia; SANTURBANO, Andrea;-DEGANI, Francisco; SALVADO, Rossana. Krisis - Tempos de Covid-19. Florianópolis: Rafael Copetti Editor, 2020.

PINTO, Tatiara Aline. O sono e o sonho na poética de Franco Fortini. Dissertação (mestrado). Universidade Federal de Santa Catarina, Centro de Comunicação e Expressão, Programa de Pós-Graduação em Literatura, Florianópolis, 2019. Disponível em https://repositorio.ufsc.br/handle/123456789/206477 . Acesso 05.02.2021.

QUIRICONI, Giancarlo (Org.). In questo mezzo sonno. Vittorio Sereni, la poesia e i dintorni. Venezia: Marsilio, 2018.

WATAGHIN, Lucia. Daquela estrela à outra. São Paulo: Ateliê Editorial, 2003.

SERENI, Vittorio. Poesie e prose. Org. Giulia Raboni. Milano: Oscar Mondadori, 2013a (e-pub).

SERENI, Vittorio. Carteggio com Luciano Anceschi 1935-1983. Org. Beatrice Carletti, Pref. Niva Lorenzini. Milano: Feltrinelli, 2013b.

SERENI, Vittorio; BETOCCHI, Carlo. Un uomo fratello. Carteggio (1937-1982). Milano: Mimesis, 2018.

SURDICH, Luigi (Org.). "Era così bello parlare". Conversazioni radiofoniche com Giorgio Caproni. Genova: Il Melangolo, 2004. 
Disponível em: www.revistafenix.pro.br

TESTA, Enrico. Cinzas do século XX: três lições sobre poesia italiana. Rio de Janeiro: 7Letras, 2016. 